\title{
Comment on Robert H. Myers: finding out what is substantive in cooperation
}

\author{
Leist, Anton
}

\begin{abstract}
Myers' offer of cooperation as a medicine for ailing moral theories is welcomed as potentially helpful, even if his handling of it is diagnosed as implicitly one-sided consequentialist. His search for an ethically "substantive way of engaging with others" is shown as not coherent with his remarks on the tasks cooperation as an ethical concept has to fulfil. Instead, it is proposed that the concept be disentangled from the micro-problems Myers' wants it to solve, and that it be read more freely, from the perspective of Rawls' conception of cooperation.
\end{abstract}

Posted at the Zurich Open Repository and Archive, University of Zurich

ZORA URL: https://doi.org/10.5167/uzh-50585

Journal Article

Published Version

Originally published at:

Leist, Anton (2011). Comment on Robert H. Myers: finding out what is substantive in cooperation. Analyse und Kritik, 33(1):141-148. 
Anton Leist

Comment on Robert H. Myers. Finding Out What is Substantive in Cooperation

\begin{abstract}
Myers' offer of cooperation as a medicine for ailing moral theories is welcomed as potentially helpful, even if his handling of it is diagnosed as implicitly one-sided consequentialist. His search for an ethically "substantive way of engaging with others" is shown as not coherent with his remarks on the tasks cooperation as an ethical concept has to fulfil. Instead, it is proposed that the concept be disentangled from the microproblems Myers' wants it to solve, and that it be read more freely, from the perspective of Rawls' conception of cooperation.
\end{abstract}

\title{
1. A New Programme
}

Robert Myers, in his intriguing article, has no smaller an aim than bringing into focus a new approach to morality which evades the quandaries both of consequentialism and contractualism. Myers characterizes consequentialism as built around the idea of impartial beneficence, and he points out its well-known problems of including individual moral rights among its moral requirements. Symmetrically, he displays contractualism, in its Hobbesian and Lockean versions, as notoriously lacking in regard to impartial beneficence, despite doing well with rights. Myers believes normative theory to be unable to integrate both these representative parts of our moral beliefs and he shies away from a bifurcated theory. Instead, he suggests the only way out of this puzzling situation would be one not "invoking moral reasoning of any sort" (131).

Strange as this suggestion may sound, it is meant to introduce his own proposal of approaching moral theory differently, basing it on a conception of cooperation. But it is not cooperation in the usual sense of cooperating for material aims, say within a firm, he is thinking of. Instead, he is interested in cooperation "to promote the good". He suggests that acting morally is "to cooperate in promoting the good", and this kind of cooperation is a "substantive way of engaging with others" (124). Even if cooperation is now meant to make some sort of contrast to moral reasoning per se, it is not clear why this could help with the unresolved problems within the two moral theories. I will come back later to this contrast between a "substantive way of engaging with other people" and a less substantive, perhaps strictly rational, analysis of social relationships 
underlying both consequentialism and contractualism. Let us first concentrate on the idea of cooperation which Myers proposes.

In order to find out what he believes "cooperating for promoting the good" implies, I will also include his approach along basically the same, if more detailed, lines in his book Self-Governance and Cooperation (1999). In the article Myers presents his proposal to make a new start, given the diagnosis of a symmetrical failure in the two moral theories, suggesting a neutral view on both. Not deeply different, but more explicitly, in his book Myers asks moral theory to answer the troubling incoherence between beneficence, prerogatives and restrictions (Myers 1999, introduction), and even though he presents them neutrally as problems of "morality's demands", it becomes clear that these problems show strong signs of a consequentialist perspective on morality. Myer's spiritual forbears Scheffler, Murphy and (in part) Nagel all seem rather more interested in how prerogatives and restrictions fit with beneficence than the other way around. The explanation of why Myers does not comment on his crucial phrase of "promoting the good", neither in his book nor his article, seems to spring just from his taking it for granted. But this is what consequentialists are in the habit to do as well.

If these observations are right, a serious restriction would inhere in Myers' proposal for a new start: presupposing a consequentialist 'good', the proposal is not all that new. What he seems to offer is this: there is a given definitionat least conceptually—of 'the good', i.e. the overall good or the good from an impartial point of view. Prerogatives and restrictions do not fit easily with this notion of good, so let us slide into the activity of "cooperating to promote the good". As I will try to point out in the next section, this is bound to become an incoherent task. If cooperation is charged with normative work concerning the good, the good should not be prefixed by any formula or idea, however formal. Otherwise, not only does the idea of cooperation become downsized normatively, but conflicts spring up regarding from which side morality is determined: from the side of cooperation or the side of its aim, 'the good'. It is a very special kind of cooperation we are asked to think of here, and its aim may conflict with its inner normativity.

In the rest of this comment I will first try to show that Myers' programme of making "cooperating in promoting the good" a basis for moral theory is indeed flawed by its consequentialist premise. In order to assign cooperation the normative work he wants it to do, neither should its aim be prefixed normatively nor should it be thought of as a purely normative or epistemic activity. Following on from this last criticism I will, secondly, take over Myers' search for a more "substantive way" for moral relationships by pointing to the normative conception of cooperation introduced by Rawls. Overall, Myers' appeal for a new beginning is right, I think, even if it should be answered in a more naturalist way than he himself favours. His own suggestion to explain normative facts "without invoking moral reasoning of any sort" (131) seems to ask for a naturalist understanding of (normatively relevant) cooperation, which he unfortunately does not consider. 


\section{2. "Cooperating to promote the good"?}

On the face of it, "cooperating to promote the good" is ambiguous. It could mean (as I take it Myers wants it to mean) that the good is somehow given and agents have to cooperate in finding out how to determine fairly the size of the demands which morality's duties and rights make on each agent. Myers, for example, shows himself recurrently impressed by the problem, discussed most extensively by Liam Murphy, of whether we have to take up the slack if others shirk their duties $(1999,5,50-2,56,82 ; 2011,133)$. The problem of how to behave in the face of others' noncompliance presupposes that it is clear what compliance is for in general. Judgement on morality's aims is pregiven.

Myers should be careful, however, about taking the good as given if he envisages cooperation to be a constructive normative mechanism. If the good is in some sense already given, why is cooperation as a normative mechanism needed, and if it is needed, how can the good be pregiven? There are, then, two readings of this formula. 'Promoting' the good could mean, in the one extreme, facing the distributive task of doing one's share in bringing about what somehow is already understood to be the good overall. This is also the problem Murphy sets himself. Alternatively, 'promoting' the good could be understood, even if a bit misleadingly, in a constitutive sense. Then cooperation would bring about moral demands in the first place, without presupposing any knowledge about the good.

Myers might object to this alternative as one he has to face, by pointing out that 'the good' is not meant to be the 'morally good', but the good in nonmoral terms. This nonmoral good, say the potential interests to be satisfied in the world, is pregiven through actually living beings, and promoting the answering of these interests morally through cooperation is not at all fraught with circularity. But this again is setting the task for moral theory in a very special, limited way typical for consequentialists. If we take the good given as the amount of interests or needs to be satisfied, and nothing else as given, there seems to be implied a normative restriction for moral demands by taking 'the whole' of interests or needs into view. Impartial beneficence seems to be the first option from this beginning, as it naturally asks for optimization of how 'the whole' of interests or needs can be fulfilled. And with this, the normative role of cooperation would be restricted as well. It would be a way of 'promoting', not constituting the good.

Myers may also protest that he is not to be read as a consequentialist with the formula "cooperating to promote the good", and overall this indeed is not clear from what he says. (In part, he indeed shows signs of understanding cooperation constitutively.) In general it seems important to be clear about three points if we want to have a better grasp on 'cooperation', normatively understood. First, why must there be conflicts between the good being given and a normatively informative concept of cooperation? Second, why should we indeed not take the good in nonmoral terms as given, as consequentialists do? Third, could cooperation be normatively informative in the fully constitutive sense hinted at? Is this a possibility at all? Let me comment on these three points in turn. 
Conflicts of the first sort are illustrated well by Myers himself, in his contrast of the consequentialist's and the contractualist's view on both agent-relative and agent-neutral reasons (135f.). The consequentialist cannot do justice to agentrelative reasons, and the contractualist cannot easily answer impartiality and fairness. Myers shows plausibly how both the contractualist approach and a cooperative one give sense to prerogatives and restrictions, but then unfortunately he is not very explicit on the advantages of the cooperative approach where the contractualist one fails.

The difference Myers thinks to exist between contractualism and a cooperative approach - given Myers' own understanding of cooperation - is not easy to see overall. Why should cooperation, understood in these special, normative and non-naturalist terms, solve problems which the contractualist approach cannot solve? Myers takes promises and obligations to result from cooperation as "a constitutive part of the way of engaging with other people that is definitive of morality" (138), and suggests thereby a constitutive version of 'cooperation'. But his attached remarks smack of an essentialist idea of cooperation and morality. Cooperation is quite a flexible phenomenon. It could as well be reconstructed in Hobbesian and Lockean contractualist terms. Cooperation is not an all-ornothing affair, which would make it necessarily authority-conferring in the way Myers thinks promissory obligations are grounded. There are different ways in which cooperation comes about, and there exist different forms of cooperation, instrumental, consensual or morally loaded ones, by respect, rights, communal aims and traditions, etc. All of these forms could, in principle, be taken up by a contractualist approach, so I do not see why contractualism could not be transformed into a cooperative approach, or why the latter may not be the best realization of contractualism.

Now to answer the second question: why should we not take the good in nonmoral terms as something both given and setting the task for moral theory or argument? The answer is: because there is a one-sided, partial understanding of the task implied in its being positioned like this. Some of the reasons for seeing this come from the very problems consequentialists involve themselves in if proceeding from this point. Consequentialists are unable to answer the appalling contrast their morality shows to our ordinary morality - something firing Myers' project (1999, chs. 1-2; this issue, sec. 2). The failure to concoct a morality from the consequentialist basis points to being misled by a wrong picture from the start. The picture is wrong because of its built-in teleology. Morality is not something answering an independent good, but is something constituting or constructing it. The question for morality is not: given all potential interests or needs to be fulfilled, how does a single set of norms manage best? It is rather: given our self-understanding as agents as $\mathrm{x}$ or $\mathrm{y}$, how can moral norms determining the reasons people have be defined so as to serve as a normative basis for a cooperative system "within which individuals can justify their pursuits to one another consistent with their self-conception"? ${ }^{1}$

\footnotetext{
${ }^{1}$ I take this part of the formulation from a slightly different, more specifically Rawlsian one by Freeman 2007, 31. Freeman develops his formulation in the context of opposing a Hobbesian
} 
Myers is undecided, if not contradictory, in his remarks as to how far cooperation is doing normative work, and more especially a normative work the contractualist cannot grasp. If I see it correctly, he wavers between assigning "cooperating to promote the good" a subordinate task à la Murphy, running along on consequentialist tracks, and working with a heavily value-loaded concept of cooperation which includes normative expectations people have towards each other. If one gives up on consequentialism, as I think one must, cooperation alone is the normative perspective from which morality can be construed. But how should this be possible? The task sounds a bit like the search for a perpetuum mobile. It can, of course, only be done by taking something morally for granted. The best answer is that not all of morality is constructed, but (voicing Rawls) something of morality "is simply laid out" (Rawls 1993, 103). What is laid out concerns the $\mathrm{x}$ and $\mathrm{y}$ in the constructive formulation offered in the last paragraph. Rawls would lay out cooperation between free and equal persons, and this is certainly a plausible basis to work on.

It would be a mistake, however, to lump construction in this epistemically foundational sense and cooperation together. If "cooperating to promote the good" does not mean something different to "arguing to promote the good", a "substantive way of engaging with other people" is hardly opened. Reasoning with each other is important, but reasoning as such bakes no bread and milks no cow. If we distinguish the special activity of epistemic cooperation from material cooperation, meant as social production of vital goods, those who (like Myers) rightly despair of the purely epistemic side of moral theories should turn to a more material concept of cooperation, and if not to material cooperation in the most concrete form of baking bread, so at least to a concept of cooperation which is not in danger of again being bogged down in a purely epistemic activity.

\section{Cooperation is for Social Success}

Before trying to focus on a more adequate conception of cooperation, some further remarks on the reasons behind the failure to date of both consequentialism and contractualism may be appropriate. As Myers' argument shows, different expectations towards cooperation may result from different diagnoses of these failures. What we expect from a normative conception of cooperation must be determined by what we expect from moral theory in general, informed by a proper understanding of its failures. Pointing to incoherencies is a good start, but as such not an explanation of them. An explanation, it seems to me, orients us rather in the direction of improving contractualism instead of consequentialism, or somehow looking for a blend of both. Without having the space to argue it explicitly, let me just put it bluntly: consequentialism misfires because of its total neglect of individual perspectives towards moral behaviour, whereas contractualism regularly is unsuccessful because of not finding the adequate mix of individual motives and reasons. There is an asymmetry of failure here: being a

account of morality's point, which is not so different to opposition toward consequentialism. More on the content of ' $x$ ' and ' $y$ ' later. 
value-ontology, consequentialism cannot be improved on, whereas contractualism can.

It may not be possible to reach an agreement on consequentialism's definite failure among philosophers. Obviously, the problems of integrating prerogatives and restrictions into impartial beneficence are grave, and unsolved. But friends of consequentialism are quick to point to similar grave problems of contractualism, disputed as they may be. ${ }^{2}$ Competition among approaches may remain undecided as long as the reconstruction of morality is largely seen as a purely intellectual affair. Starting from either a global or an individual view on morality seems to be two possible options, in principle, without an intellectual premium for either the one or the other. If one, however, brings the additional interest in motivation for morality into play, contractualism likely wins the race. Considering motivation is of interest under the aspect of integrating motivation with reasons, either normatively - answering the so-called 'motivation problem': why should I be moral? —or explanatively or naturalist-integrating normative and explanative reasons for morality. Consequentialism has to outsource such questions and cannot integrate them on a basic level into its normative approach. Contractualists, on the other hand, make the different forms of practical reasons, motivational and judgemental, the central part of their theories. Only if the fate of contractualism to be successful would lie in its also being largely intellectualist without any basis in motives, could consequentialists shrug off this asymmetry.

This problem of finding the adequate mix of intellectual and motivational powers is the site where the conception of cooperation is perhaps placed best. To find the right conception of cooperation might be seen as finding the middleground between different capacities humans come with and different capacities behind moral behaviour. If one were to distinguish these capacities as ones of (anti-moral) motivation and (moral) reason, one would again have the puzzle at hand of how reason could be motivating. ${ }^{3}$ Instead, it seems better to distinguish between capacities both being reflective and motivating, but supplementing each other in a way somehow optimally matching human psychology. It seems to me that, given these expectations, Rawls' description of morally relevant capacities as the "reasonable" and the "rational", both being complementary and "working in tandem", is the best one presently available (Rawls 1993, 48-54).

Rationally, humans look for what is best for them, reasonably, they are "ready to propose principles and standards as fair terms of cooperation and to abide by them willingly, given the assurance that others will likewise do" (Rawls 1993, 49). Being disposed as reasonable is "related to [...] act morally" and not per se to act morally in any substantial or fixed sense. Important in the present context: being reasonable is not to be identified with being "moved by the general good" (Rawls

\footnotetext{
${ }^{2}$ One could dispute, for example, that Scanlon should not be able to answer the conflict between rights and numbers, as Myers admonishes (131). It seems to me that Scanlon is quite successful in this: 1998 , ch. 5, sec. 9. His solution still seems to me the best presently on offer.

3 Not even Kant who, as we remember, was famous for his dichotomies, conceived of motivation and reason standing fully apart, as he saw a sentiment of respect springing from 'pure practical reason', which means he thought the practically rational and the sentiments to be narrowly related. He got it wrong, unfortunately, by thinking the first to be primary and nonnatural.
} 
1993, 50), and therefore does not include the same idea as consequentialism. The reasonable as complementary to the rational is dependent on the rational, i.e. it is also fixed to the individual perspectives of others, even if many others. As the dependency between the reasonable and the rational is mutual, it is not reductive, but covers two distinct capacities of humans. To find out about both successful justification and the right morality is to bring these two capacities into proper balance.

How does cooperation come in here? Not only would these capacities be without sense if they were not realized within cooperation, they would also not have sprung up without cooperation in the first place. If we accept Rawls' two-layer view of persons, we should also accept a two-layer view of cooperation. Cooperation is both for mutual advantage and for reasonable conditions governing activities to this advantage. The prominent moral element in these conditions will be, as is easily visible from Rawls' proceedings, principles of justice directed at basic institutions in a society. Justice being in the foreground of interest in moral principles starting from such a conception of cooperation, the rest of morality need not, to my mind, be derived from other sources. As Rawls himself, at least in the Theory of Justice, was of a different opinion, ${ }^{4}$ let me conclude this comment with short remarks on the presumptive weaknesses of approaching morality from such a heterogeneous concept of cooperation.

Even if the psychological bases of cooperation have been made clearer so far, what is that cooperation meant to be up to now? We seem no longer to be in the cooperation for 'promoting the good' in an open sense, but we are also not talking about cooperating in the growing of potatoes. What is important and is changing the picture in Rawls' conception is its element of mutual advantage, something inherent in cooperatively growing potatoes, and of course also in the endless multitude of all instrumental cooperative endeavours among humans. Humans cooperate primarily because of wanting to be more successful in reaching the material aims they have, and if these aims may not be purely self-interested ones, they nearly always have a self-interested side. Humans do not cooperate primarily to find out moral principles, let alone solve philosophical quandaries in moral theories. The moral side of cooperation rides piggyback on the material one, and not the other way around, but the material one alone would not do either.

'Cooperation' in this Rawlsian, two-layered sense seems to me an important ethical concept because it integrates the different, but complementary capacities which both make morality necessary and give rise to it. Cooperation would hardly be possible without moral principles, and if it did not include a reasonable sense of fair principles, it would also not lead to a form of cooperation potentially agreeable to all sides - and indirectly also not to a form of morality potentially agreeable to all sides. Even if still a form of contractualism, talk of cooperation has the advantage of letting us see morality not as self-standing, but as a part, the normative part, of non-morally motivated social action. Seeing morality as

${ }^{4}$ In Theory Rawls distinguished the individual duties often associated as typical for 'morality', as 'natural duties' from the social duties of justice and gave them a slightly incoherent justification from the original position. 
functionally dependent on cooperative social action guides moral theory in many helpful ways. It gives us a strong argument, for example, for why morality is primarily centring on justice and not on absolute individual rights. And it helps us to see, for example, how Myers in his consequentialist beginnings unnecessarily takes agent prerogatives to be on the same level as beneficence and restrictions. If it is possible to determine prerogatives 'objectively' at all, it is not to be done within the same argument dealing with demands for, say, rights to welfare and freedom. As again Rawls makes clear, it is one thing to devise moral rights for a whole society and quite another to devise moral rules for "communities" or "associations" (1993, 40-3).

It seems to me that if one is looking for a "substantive way of engaging with others", one in opposition to mere reasoning, as Myers does, one should end up with such a mongrel version of cooperation. Of course, this is not what most moral philosophers will accept easily, among them perhaps Myers himself. In philosophical tradition, the idea pervades that morality arises somehow fully outside of anything else, and especially outside of more concrete forms of social action. With this idea in mind, cooperation is not a normatively constitutive concept for morality at all, and accordingly it plays no role in the philosophical tradition. But the failure of moral theories to reflectively make good on our intuitive morality should teach a lesson as to where morality is to be located better.

The conception of cooperation helpful for moral theories takes out of the many human cooperative activities just this view which exemplifies the two capacities making socially coordinated activities most fruitful, both socially and individually. Working with a stylized version of this conception, one within a perhaps larger class of what is modelled by Rawls' 'original position', enables theorists to derive moral principles from this basis. The conception of cooperation which offers itself as the site of moral argument is the one which proves to make human cooperation most successful, and more fine-grained descriptions of cooperation than Rawls' may be possible. Such a project will be naturalist in a sense, since the occasion when cooperation is most successful will only be learned from real social action and not from abstract ideas.

\section{Bibliography}

Freeman, S. (2007), Justice and the Social Contract, Oxford Myers, R. (1999), Self-Governance and Cooperation, Oxford - (2011), Cooperating to Promote the Good, this issue

Rawls, J. (1993), Political Liberalism, Cambridge/MA

Scanlon, T. (1998), What We Owe to Each Other, Cambridge/MA 